Research Article

\title{
Evolution Analysis of Microseismic Events before and after Mining through Large-Scale Weak Zone with High Confined Water
}

\author{
Jing Jia $\left(\mathbb{D},{ }^{1}\right.$ Xianjie Hao $\mathbb{D}^{, 2,3,4}$ Guanghui Zhao ${ }^{\mathbb{D}},{ }^{4}$ Yubao Li ${ }^{\mathbb{D}},{ }^{1}$ Xiaoyu Chuai $\left(\mathbb{D},{ }^{1}\right.$ \\ Lei Huang $\mathbb{D}^{4},{ }^{4}$ Guangyao Pan $\left(\mathbb{D},{ }^{4}\right.$ Yingnan Wei $\mathbb{D}^{4},{ }^{4}$ Kai Chen $\mathbb{D}^{4},{ }^{4}$ Ruilai Huang $\mathbb{D}^{4}{ }^{4}$ \\ and Rongcheng Zhan (iD) \\ ${ }^{1}$ Hebei Coal Research Institute, Xingtai, Hebei 054099, China \\ ${ }^{2}$ Beijing Key Laboratory for Precise Mining of Intergrown Energy and Resources, \\ China University of Mining and Technology (Beijing), Beijing 100083, China \\ ${ }^{3}$ Key Laboratory of Safety and High-Efficiency Coal Mining, Ministry of Education (Anhui University of Science and Technology), \\ Huainan 232001, China \\ ${ }^{4}$ School of Energy and Mining Engineering, China University of Mining and Technology (Beijing), Beijing 100083, China
}

Correspondence should be addressed to Xianjie Hao; haoxianjie@cumtb.edu.cn and Guanghui Zhao; zqt1900101063g@ student.cumtb.edu.cn

Received 9 April 2021; Revised 7 July 2021; Accepted 15 July 2021; Published 3 August 2021

Academic Editor: Youjun Ning

Copyright ( 2021 Jing Jia et al. This is an open access article distributed under the Creative Commons Attribution License, which permits unrestricted use, distribution, and reproduction in any medium, provided the original work is properly cited.

\begin{abstract}
The existence of large-scale weak zone will have a great adverse impact on coal mining in high confined aquifer. Taking the Wutongzhuang Coal Mine which is threatened by high-pressure water as an example, this paper studies the difference between the microseismic events before and after mining and analyzes the influence of the large size weak zone on the coal mining on the confined aquifer. The research results show that the microseismic characteristics of the large soft weak belt are small number of events, the spatial distribution of events is concentrated, and the energy level is large. The amplitude of microseismic events is higher, and the proportion of large events in microseismic events is larger than that of small events; the characteristics of microseismic events caused by mining face mining are that the number of events is more, the distribution of events is loose, the distribution of roof and floor is more, the energy level is less, the amplitude is smaller, and the proportion of small and medium events in microseismic events is larger than that of large events. Due to the joint influence of large-scale weak zone of floor and mining, the floor in the middle area of working face is affected by mining, the number of microseismic events in each aquifer increases suddenly, the karst fissures between the aquifers are further developed, and there is a trend of transfixion. Therefore, measures such as floor grouting should be taken to reinforce the large-scale weak zone before mining.
\end{abstract}

\section{Introduction}

Mine water disaster is one of the five major disasters in coal mines in China [1]. Coal mine water inrush accidents account for a large proportion of coal mine disasters, causing heavy losses to the country and people's lives and property [2]. According to statistics, about $60 \%$ of coal mines in China are affected by confined water to varying degrees, and the area and the severity of water disaster rank first among major coal-producing countries in the world [3]. Take Wutongzhuang Coal Mine as an example. It is typical coal mining on confined water in the "three underground and one waterborne circumstances" special mining [4]. In recent years, with the increase of mining depth, the Wutongzhuang Coal Mine has been more and more threatened by high-pressure o.l. water $[5,6]$. Even if water disaster prevention measures are taken, water inrush accidents still occur [7]. Therefore, studying the mining of coal seam on confined water and 
avoiding the occurrence of water inrush from the floor are an urgent problem to be solved [8].

China is a country that started to study coal mining on high confined water relatively early in the world and has achieved a lot of results. Xie et al. [9] started from the mechanism of hydraulic fracturing and analyzed the permeability changes to infer the risk of water inrush from the floor and introduced the concept of damage. $\mathrm{Xu}$ et al. [10] studied the mining failure of coal mining floor under high confined water and the formation and evolution of water inrush channels through on-site monitoring and numerical simulation. $\mathrm{Li}$ and $\mathrm{Xu}$ [11] established a physical model to prevent water inrush disasters from the collapse column using the comprehensive methods of theoretical analysis, similar simulation, and digital simulation. Zhao et al. [12] put forward the key technology of advanced treatment of o.l. water damage in the ground area, and it has been widely used. Dong et al. [13] and Wang et al. [14] put forward the idea of using a weathering zone at the top of the Ordovician limestone which has better water blocking performance as a water-repellent layer, and they conducted a study on its availability and established a criterion for the thickness of the rock section on top of Ordovician limestone. Xu et al. [15] used borehole ultrasonic detection, core indoor ultrasonic transmission, and point load test methods to study the damage and destruction degree of the floor rock before mining working face in the upper and lower coal seams of the confined water, and they obtained the rock elastic modulus. The density, lithology, and completeness of rock mass show a nonlinear positive correlation. Ma [16] combined method of transient electromagnetic method and radio wave perspective method to comprehensively detect the internal water-conducting structure of the working face under the effect of high confined water and achieved good results. Wei et al. [17] and others used numerical simulation and similar simulation methods to analyze the degeneration characteristics of the roadway under the effect of high confined water. Chen et al. [18] used the knowledge of mechanics combined with the "drilling double-ended side leakage plugging device" to study the evolution of cracks in the mining rock mass under high confined water. $\mathrm{Xu}$ and Gao [19] established a mechanical model to theoretically analyze the mechanism of water inrush from a working face cross-fault under high confined water conditions. Wang et al. [20] analyzed the failure law of complex rock during UCA mining and proposed a method for predicting the danger zone of support fractured water inrush. Yu et al. [21] used the fractal dimension method to partition the structural complexity of the study area and evaluated the risk of water inrush from the deep coal seam floor by mining above the confined aquifer in the mining area. Duan and Zhao [22], by analyzing some water inrush cases, put forward four main factors that affect water inrush from coal seam floor and established a mechanical model for the homogeneously broken and weak rock layer of the floor water-insulating layer. $\mathrm{Li}$ [23] introduced the development history of various geophysical prospecting technologies such as underground electrical methods, transient electromagnetics, electrical perspective, radio wave tunnel perspective, and channel wave seismic in China and discussed the development direction of the discipline.

The microseismic monitoring method has been widely used in coal mines. In recent years, many scholars have made a series of achievements in the field of microseismic events. Ge and Han [24] proposed an imaging method for reversetime migration of the structure below the microseismic zone. Lou et al. [25] used microseismic monitoring methods to analyze and study the stress conditions in the goaf and the rearrangement of the fracture zone. Wang et al. [26] proposed a source-independent objective function based on convolving reference traces, which avoids the cycle jump phenomenon caused by unknown sources and improves the accuracy of estimating the location of the seismic source. Hao et al. $[27,28]$ studied the fracture characteristics of coal under dynamic load through uniaxial compression tests and studied the influence of bedding cleats on it, and they found in subsequent studies that microseismic events occur when the coal bedding dip is $45^{\circ}$ at most. Hao et al. [29] used a quantitative analysis method to construct three physical models and combined numerical simulation to analyze the influence of the main principal stress directions on the long axis of the tunnel on the stability of the underground tunnel. Zheng et al. [30], based on the limit equilibrium method and genetic algorithm, proposed a new method for stability assessment of ABRS considering seismic inertial forces. The effects of seismic and mechanical properties of rock strata on the failure mechanism of ABRS are discussed. Zhang et al. [31] proposed a new method based on VMD to distinguish between coal and rock fracture and blasting vibration microseismic signals by processing the signal. Chen et al. [32] evaluated the effect of hydraulic fracturing by analyzing the number of microseismic events and energy changes caused by high-pressure hydraulic fracturing. The Brune model and grid search method were used to calculate the source parameters, and the relationship between M-0 and other source parameters was analyzed. The relationship between M-w (moment magnitude) and M-L (local magnitude) of microseisms induced by hydraulic fracturing is obtained. Amad et al. [33], through the joint inversion of source location and distance tensor, reconstructed the space and role of (micro) seismic events and constructed a full-waveform technology. Estay et al. [34] obtained the b value of seismic activity related to mining by studying the time decay law of seismic activity after rockburst and large-magnitude events occurred in the aftershock sequence of the mine. Liu et al. [35] proposed a microseismicity-based method for the dynamic estimation of the potential rockburst scale during tunnel excavation.

In summary, it can be seen that there are a large number of results in exploration, mechanical models, and similar simulations in high-pressure water mining. However, there are few studies on the microseismic characteristics of excessively large-sized weak zones before mining. Therefore, this paper uses the data collected by the microseismic monitoring system to study the difference between the large-scale weak zone near the F702-11 fault in the front 
floor before and after the mining of Wutongzhuang Coal Mine 182703 working face, and it analyzes the impact of large-size weak zones on coal mining above confined aquifers and provides technical guidance for coal mine safety production.

\section{Project Profile}

Wutongzhuang Coal Mine is located in Handan City, Hebei Province. It is one of the main mines of Jizhong Energy Fengfeng Group, with a design production capacity of 3.0 Mt/a. The hydrogeological conditions are extremely complex, and the ground temperature of the mine affected by the geological structure is higher than that of other mines in the group [36, 37].

The 182703 working face is located in the seventh mining area, the east is the designed 182704 working face, the west is the 182702 mined area, the south is the F2-2 fault, and the north is the south belt transportation lane with no other excavation condition. The No. 2 coal seam is mined at the working face, the coal bulk density is $1.35 \mathrm{t} / \mathrm{m}^{3}$, the mining area is $145071 \mathrm{~m}^{2}$, the industrial reserves are $0.722 \mathrm{Mt}$, and the recoverable reserves are $0.686 \mathrm{Mt}$. The strike length of the working face is $683 \mathrm{~m}$, with an average of $683 \mathrm{~m}$; the inclination length is $94 \mathrm{~m} \sim 252 \mathrm{~m}$, with an average of $212 \mathrm{~m}$; the inclination of the working face is $1^{\circ} \sim 36^{\circ}$, with an average of $25^{\circ}$; the maximum coal seam thickness is $4.2 \mathrm{~m}$, the minimum is $3.0 \mathrm{~m}$, and the average is $3.69 \mathrm{~m}$. The buried depth of the working face is about 660 meters, and the direct top lithology is sandy shale, which is brittle and compact.

\section{Distribution of Large-Size Weak Zones in the Working Face}

According to the data provided by the Wutongzhuang Coal Mine Geology Department, in the 182703 working face, there are many weak zones dominated by faults, and the fault occurrence is shown in Table 1. Figure 1 shows the distribution of abnormal weak bands on the working face measured by the transient electromagnetic method. Figure 2 shows the cross-sectional view of the weak fault zone in the working face.

\section{Comparative Analysis of Microseismic Events before and after Mining}

\subsection{Construction of the Microseismic Monitoring System}

4.1.1. Layout of the Microseismic Monitoring System. There are 11 geophones arranged in the upper and lower tunnels and 2 underground monitoring substations for a total of 15 channels on the 182703 working surface of Wutongzhuang Mine. Among them, 3\# and 7\# are threecomponent detectors, the others are single-component detectors, $1 \# \sim 5 \#$ detectors are located in the lower groove, and $6 \# \sim 11 \#$ detectors are located in the upper groove. There are 24-bit digital microseismic acquisition substations, respectively, in the 182703 transportation roadway and the 182703 return airway, with a sampling frequency of $5 \mathrm{kHz}$.
The monitoring layout is shown in Figure 3. In order to avoid the influence of the loose circle of the roadway, the geophones are buried at a depth of $6 \mathrm{~m}$ and the spacing is about $100 \mathrm{~m}$.

4.1.2. Transmission and Processing of Microseismic Monitoring Data. The microseismic monitoring data is continuously collected in real time, and the underground optical fiber is directly transmitted to the surface switch of Xingdong Coal Mine and transmitted to the microseismic monitoring and monitoring center of the Academy of Coal Science through the Jizhong Energy LAN (Figure 4).

The 182703 working face monitoring system was set up in April and began to collect data. The working face started mining on May 17th. We compared the number of events, energy, amplitude, and spatial distribution in the microseismic monitoring data collected from April 1st to April 10th and May 18th to May 27th to analyze the impact of mining work on microseisms.

4.2. Comparative Analysis of the Number of Microseismic Events before and after Mining. Figure 5 shows the statistics of the number of events before and after mining. From April 1st to April 10th, before mining, there were a total of 340 events collected. The number of events on April 10 was the least, with 15 events, and the number of events on April 3 was the most, with 55 events, with an average of 34 events per day. From May 18 to May 27 after the mining, there were a total of $820 \mathrm{mi}-$ croseismic events collected, of which the number of events on May 19 was the least, with 47 events, and the number of events on May 24 was the most, with 132 events, with an average of 82 events per day. After querying the data of the mine, it was concluded that the increase in microseisms on May 24 was caused by the roof first weighting.

From the comparison of the data in Figure 5, in terms of quantity, it can be seen that the number of microseismic events affected by mining activities has increased significantly in May.

4.3. Comparative Analysis of Microseismic Energy before and after Mining. Figure 6 shows the comparison of microseismic energy before and after mining. Figure 6 shows that, from April 1st to April 10th, before mining, the minimum energy was $4691 \mathrm{~J}$ on April 8, the maximum energy was $4614966 \mathrm{~J}$ on April 5, and the average daily energy was $1002882 \mathrm{~J}$. After mining from May 18 to May 27, the lowest energy was $2801 \mathrm{~J}$ on May 21, the highest energy was $658864 \mathrm{~J}$ on May 27, and the average daily energy was 119664 J. It can be seen that the energy in April is an order of magnitude higher than that in May, so it can be concluded that before the working face was mined in April, the cause of the microseismic event was due to the existence of a weak zone in front of the working face, which was affected by the geological tectonic movement of the coal mine, causing a large microseismic event, so the energy is huge. The microseismic event in May is caused by mining activities, although the number is large, but the energy is much smaller than the energy generated by the weak zone. 
TABLE 1: Occurrence characteristics of weak zone in 182703 working face.

\begin{tabular}{lccccc}
\hline Construct name & Trend & Tendency & Dip angle $\left(^{\circ}\right)$ & Type & Falling head $(\mathrm{m})$ \\
\hline F702-10 & $\mathrm{N} 5{ }^{\circ} \mathrm{E}$ & $\mathrm{SW}$ & 65 & Normal fault & 2 \\
F702-11 & $\mathrm{N} 58^{\circ} \mathrm{W}$ & $\mathrm{SE}$ & 70 & Normal fault & 1.2 \\
F703-12 & $\mathrm{N} 18^{\circ} \mathrm{E}$ & $\mathrm{SE}$ & 80 & Normal fault & 7.2 \\
F703-13 & $\mathrm{N} 24^{\circ} \mathrm{E}$ & $\mathrm{SE}$ & 80 & Normal fault & 2.7 \\
F703-15 & $\mathrm{N} 44^{\circ} \mathrm{E}$ & $\mathrm{SE}$ & 67 & Normal fault & 6 \\
F703-16 & $\mathrm{N} 50^{\circ} \mathrm{E}$ & $\mathrm{SE}$ & 55 & Normal fault & 3.5 \\
\hline
\end{tabular}

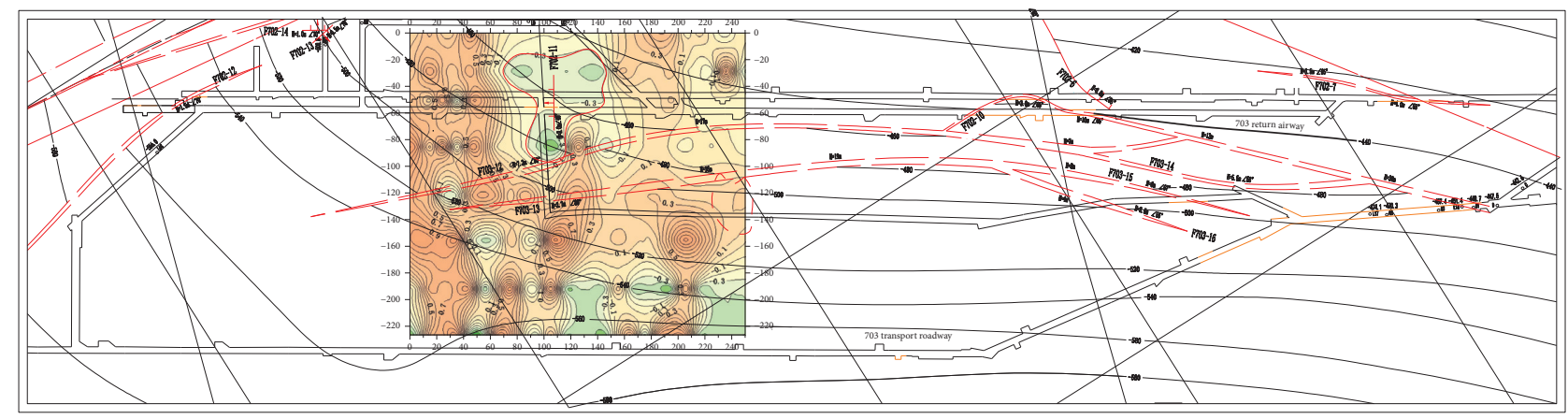

FIGURE 1: Distribution range of weak zone in 182703 working face.

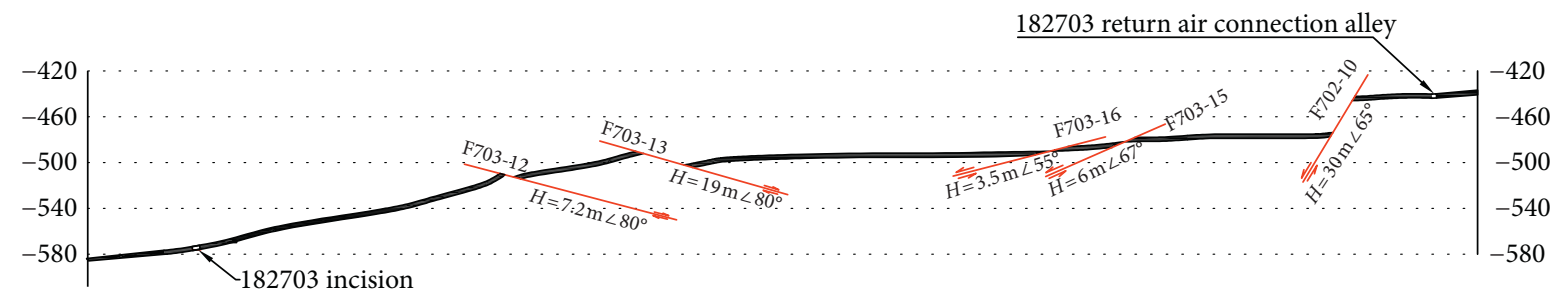

FIGURE 2: Fault profile in working face.

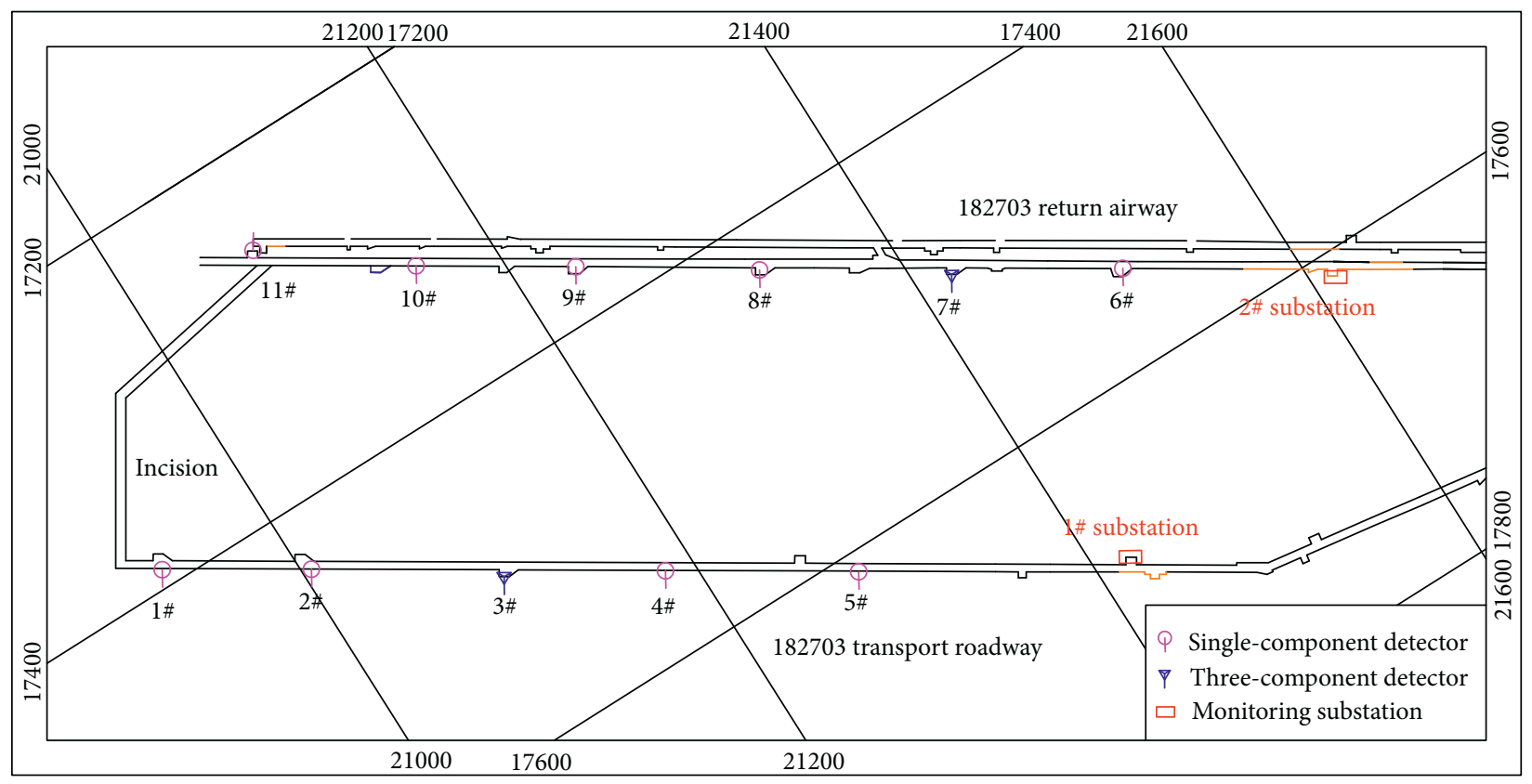

Figure 3: Microseismic monitoring layout of 182703 face in Wutongzhuang Mine. 


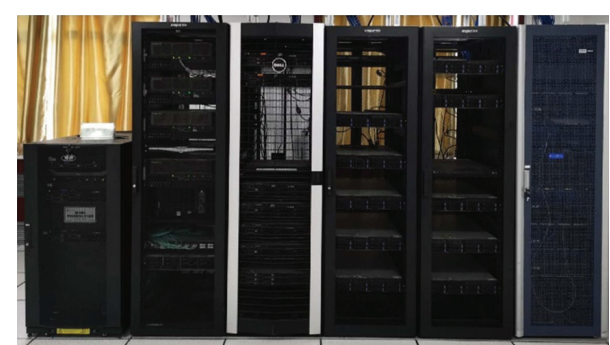

Figure 4: Microseismic monitoring center.

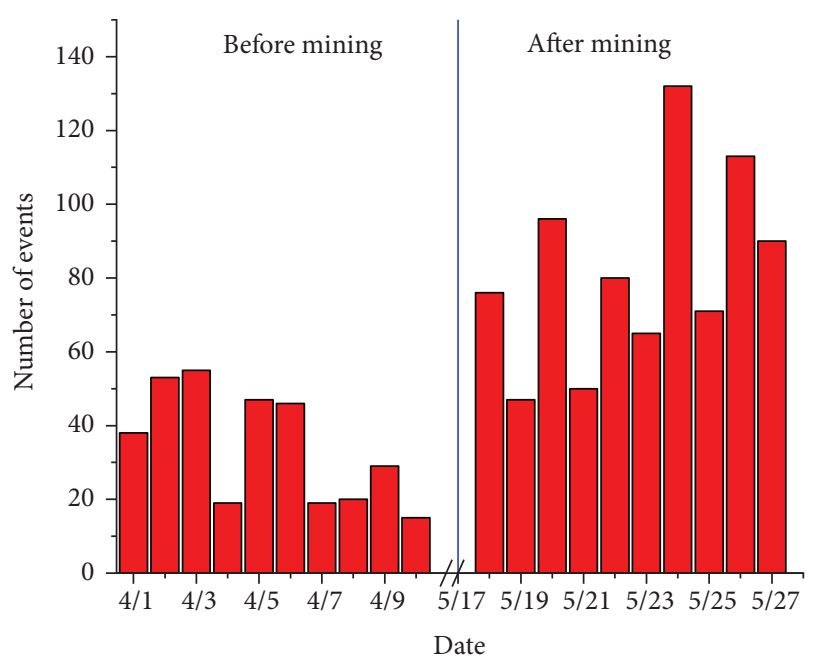

FIGURE 5: Comparison chart of the number of microseismic events before and after mining.

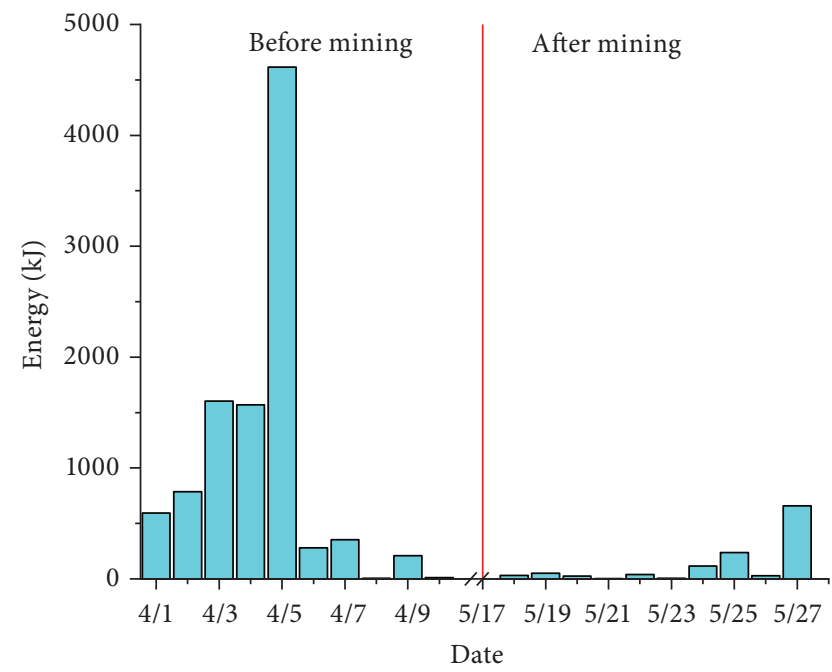

FIGURE 6: Energy comparison graph of microseismic events before and after mining.

Figure 7 is a graph of cumulative energy and cumulative events. It can be seen from Figure 7 that the cumulative number of microseismic events is higher after mining, but in terms of cumulative energy of microseisms, the large-size weak zone was affected by the geological tectonic movement resulting in the dislocation of the large-size weak zone before mining, which caused a large microseismic event, resulting in a surge in energy, which was an order of magnitude higher in energy data than after mining.

It can be seen from the comparison diagrams of Figures 5-7 that the microseismic events monitored in April were caused by the large-scale weak zone in front of the working face that was affected by the movement of geological tectonic movement and caused the large microseismic event. Its manifestation is large energy and small number of events. The microseismic events monitored in May are microruptures caused by the mining activities. The manifestation is low energy and large numbers of microseismic events.

\subsection{Comparison of the Amplitude of Microseismic Events} before and after Mining. Figure 8 is a comparison diagram of the amplitude of microseismic events before and after mining. It can be seen that, from April 1st to April 10th, before mining, there was a microseismic event with a minimum amplitude of 0.8597 on April 1st and a maximum microseismic amplitude of 4.2951 on April 7th with an average amplitude of 2.0751, and the microseismic amplitude distribution was more even. From May 18th to May 27th, after mining, there was a microseismic event with a minimum amplitude of 0.0934 on May 23rd and a microseismic event with a maximum amplitude of 4.8481 on May 18 th, with an average amplitude of 1.3903 , and there were more small amplitude events. Therefore, it can be seen from the comparison diagram of the amplitude of the microseismic event that before the working face was mined in April, the large-scale weak zone was affected by the geological tectonic movement and caused a large microseismic event. Although the number of events is small, the energy and amplitude are relatively large. In May, the working face was affected by the continued mining activities to cause small ruptures. There were many microseismic events, but most of them were small events with small amplitude and low energy.

\subsection{Analysis of the Spatial Distribution of Microseismic Events before and after Mining}

4.5.1. Distribution Characteristics of Microseismic Events in Each Aquifer. Figures 9 and 10 are, respectively, the spatial distribution of microseismic events. The sphere in the figure represents the microseismic event, the size of the sphere represents the amplitude of the microseismic event, and the black curved surface is the No. 2 coal seam. By comparing the spatial distribution map of microseismic events before and after mining, it can be seen that the microseismic events before mining are mainly floor events, and the distribution range of the events is concentrated between -400 and -650 meters. Although the microseismic events caused by mining activities are still mainly floor events, the roof events have obviously increased. From the distribution range, it can be seen that the distribution range of microseismic events after mining is mainly concentrated between -400 and -800 meters, but there are still a small number of microseismic 


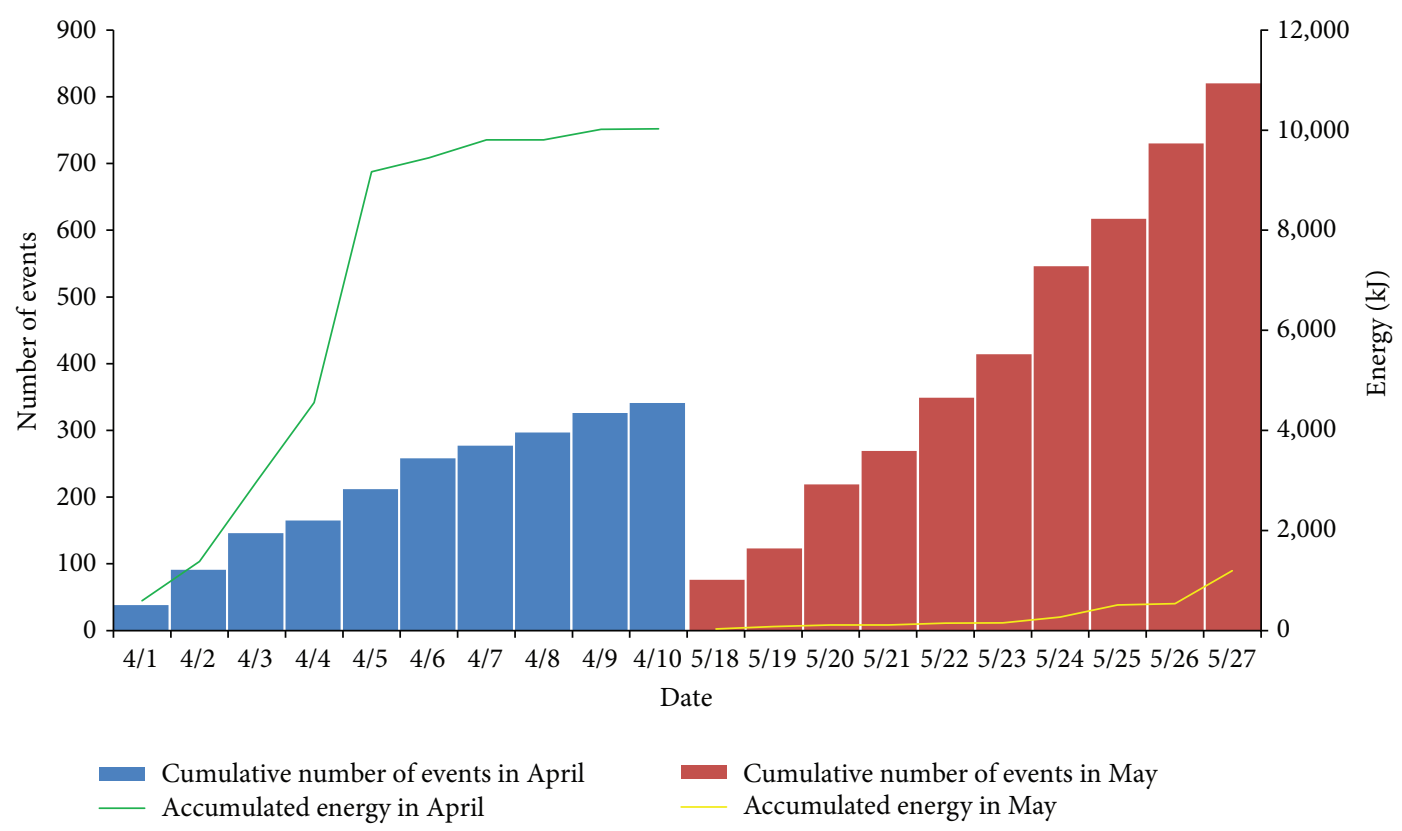

FIgURE 7: Comparison of cumulative number of microseismic events and accumulated energy before and after mining.

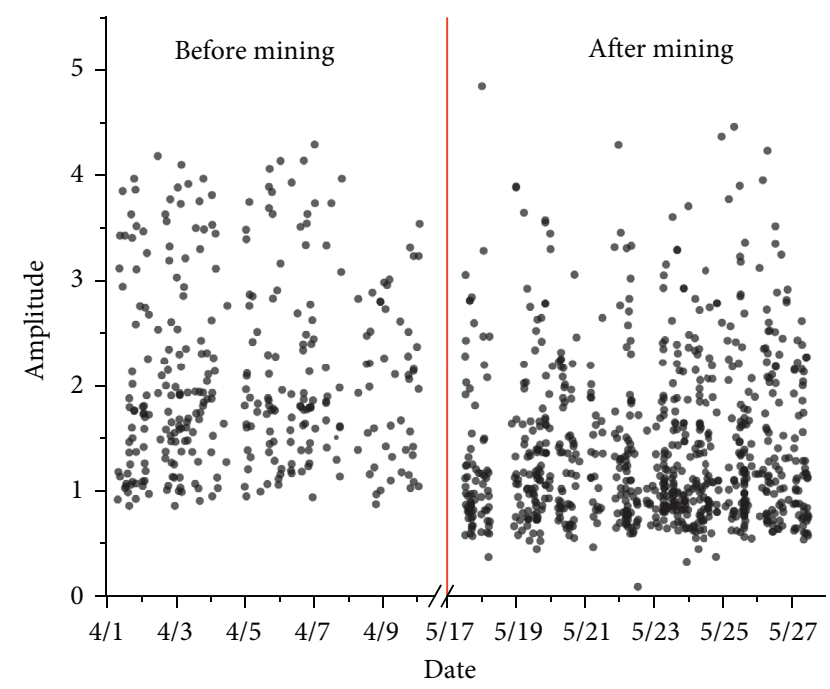

FIGURE 8: Comparison chart of microseismic events before and after mining.

events extending to the top -200 meters and the bottom -1000 meters. Therefore, the distribution of microseismic events caused by mining is wider, with a large number of microseismic events on the floor and the roof, but the magnitude of the microseismic events is smaller than that of the large-scale weak band movement.

The microseismic event distribution diagram (Figures 11-14) was established through the microseismic data collected by the microseismic monitoring system. From Figure 11, it can be seen that the microseismic events generated by tectonic activities in April were distributed in the middle of the area on the plane, and the events that occurred in the Ordovician limestone were mainly concentrated in the area of the F702-11 fault and extending to
F2-2 fault area, the distribution range of events that occurred in the Ordovician limestone is relatively concentrated. It can be seen from Figure 12 that the number of events that occurred in the Ordovician limestone after mining in May increased significantly compared to Figure 11, and they were mainly distributed near the F702-11 fault area. However, the number of events that occurred in the Ordovician limestone was more dispersed than that in May, from the shallow part of 2\# coal to the Yeqing layer mainly concentrated near the transport roadway and the return air trough and extending to the open-off cut. The distribution of events is relatively concentrated. The analysis reason is that, from the shallow part of 2\# coal to Yeqing layer mainly affected by mining pressure, Ordovician limestone interval is mainly affected by the o.l. water pressure.

Figures 13 and 14 are cross-sectional views perpendicular to the transport roadway and the return air trough. From Figures 13 and 14 it can be seen that microseismic events occur in all aquifers, but the proportion of events that occurred in the Ordovician limestone in the distribution of microseismic events in May has increased significantly compared to the proportion of events that occurred in the Ordovician limestone in the distribution of microseismic events in April, and the proportion of occurrences of microseismic events in the floor of Shanfuqing-the floor of Daqing has decreased. At the same time, combining the microseismic events of each aquifer in Figure 15, it can be seen that the large-scale weak zone was distorted by the geological tectonic movement in April, which mainly occurred in the floor of Yeqing-the floor of Fuqing area, which caused a significant increase in the proportion of microseismic events in this area, and after the mining in May, since no tectonic activity has occurred so far, it is only affected by mining activities, so the distribution of microseismic events in each aquifer is relatively even. 


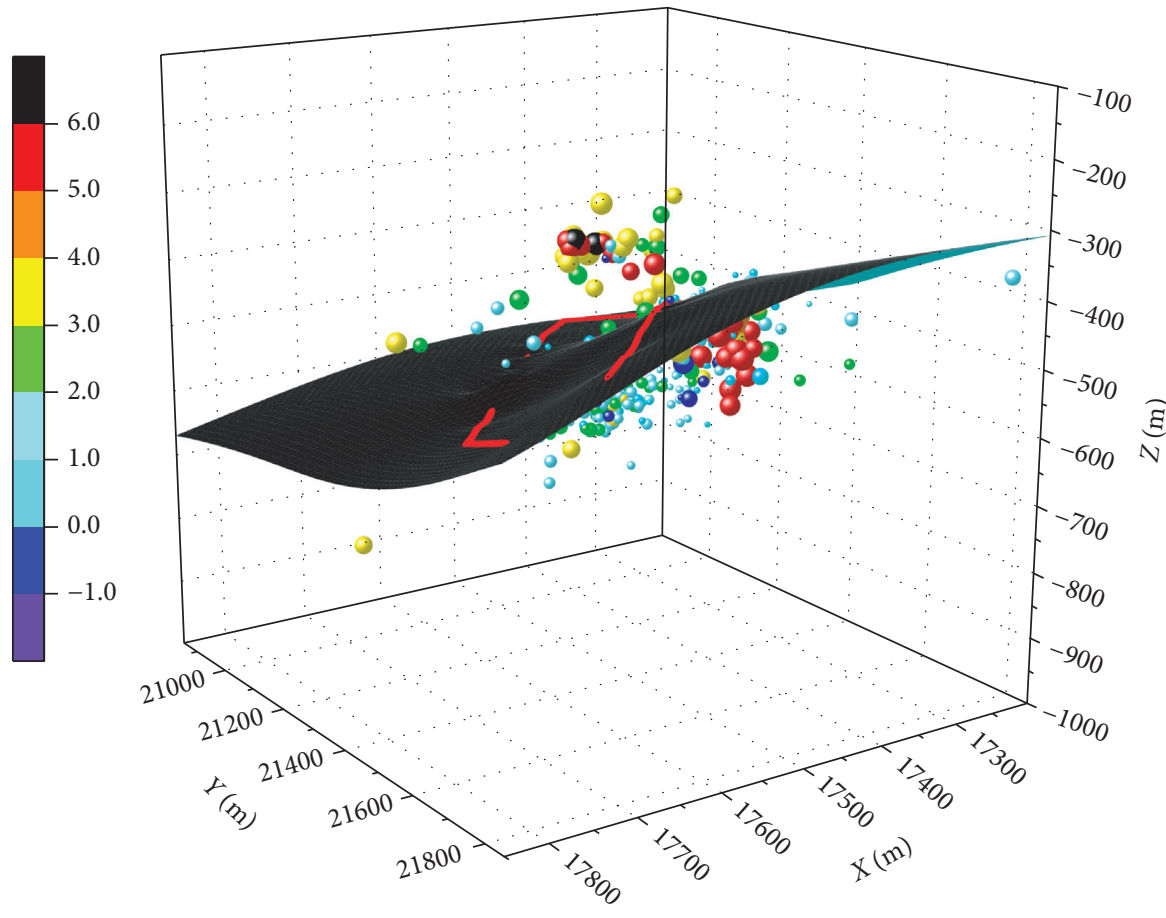

- Microseismic events

Coal seam

Tunnel

FIgURE 9: Spatial distribution map of microseismic events before mining.

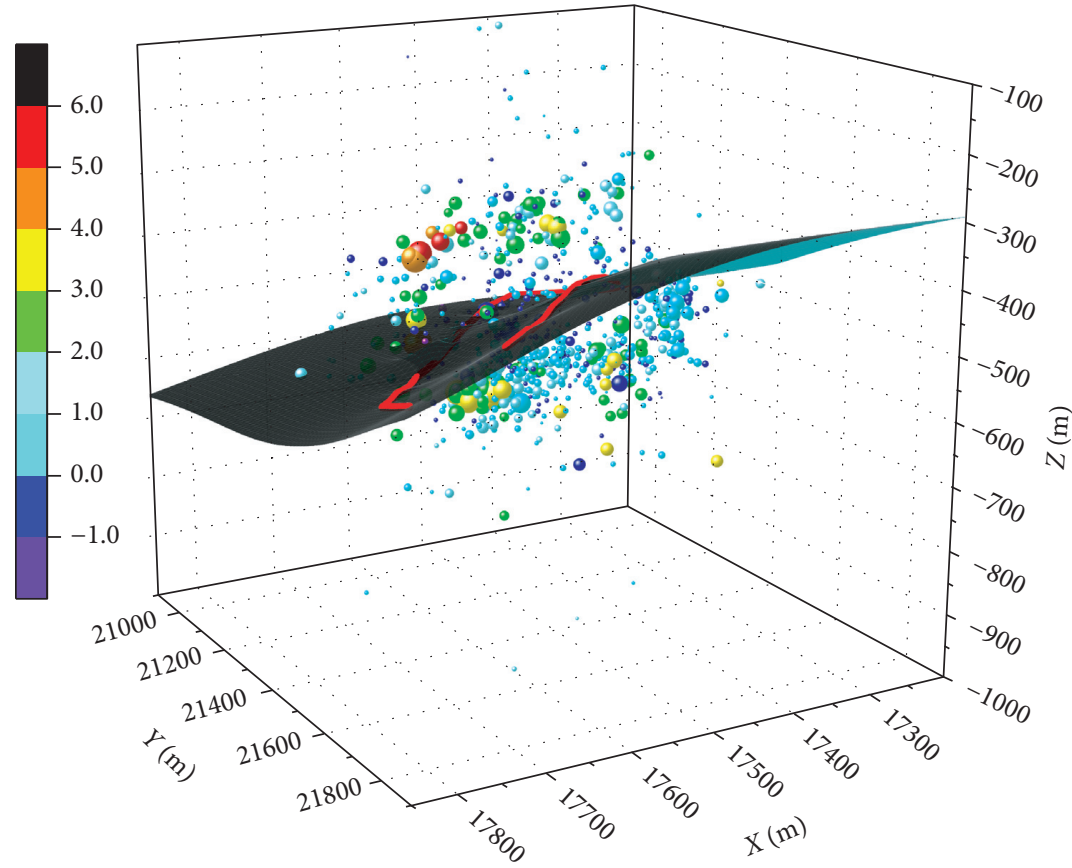

Microseismic events

Coal seam

Tunnel

FIGURE 10: Spatial distribution map of microseismic events after mining. 


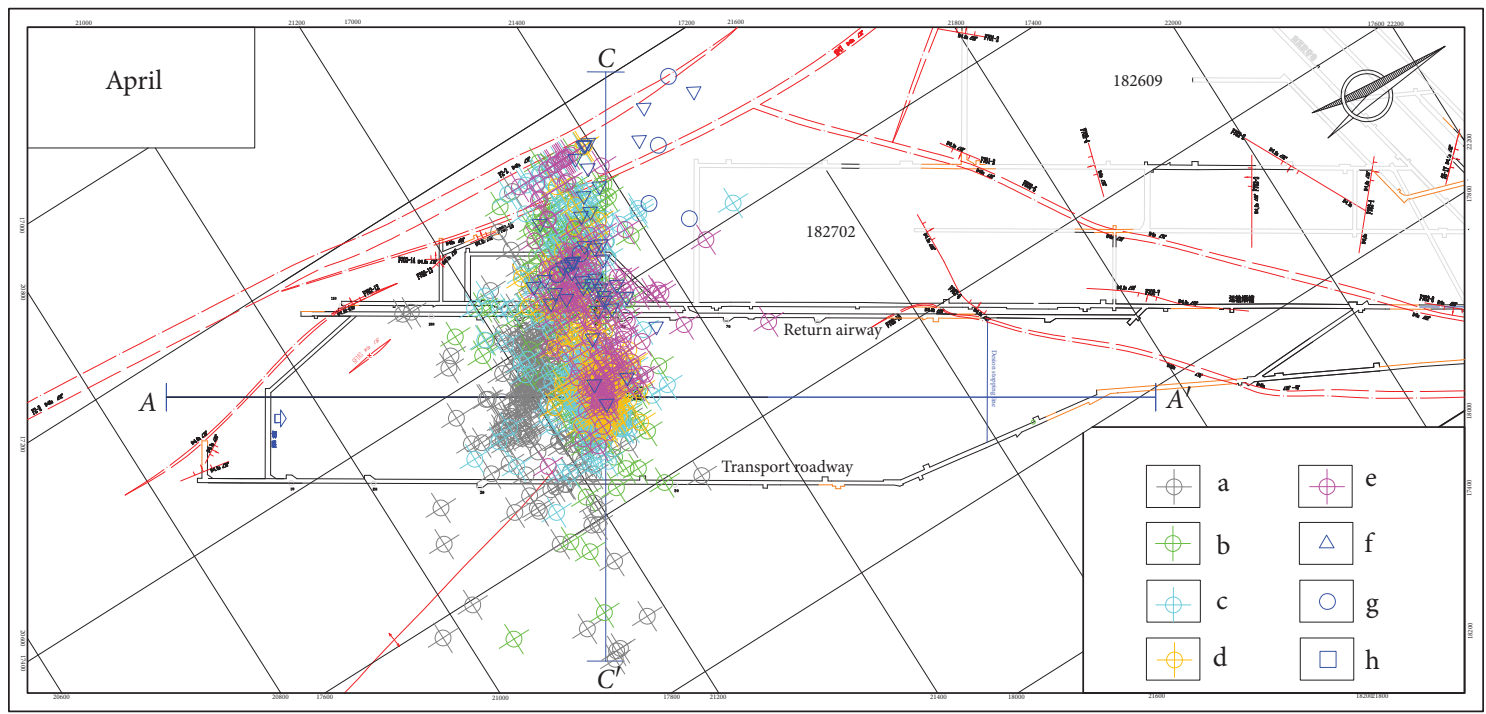

Figure 11: Distribution plan of microseismic events in April. a: shallow of 2\# coal; b: floor of 2\# coal-floor of Yeqing limestone; c: floor of Yeqing limestone-floor of Fuqing limestone; d: floor of Fuqing limestone-floor of Daqing limestone; e: floor of Danqing limestone-roof of Ordovician limestone; f: Ordovician limestone (0-50 m); g: Ordovician limestone (51-150 m); h: Ordovician limestone (150 m-deep part).

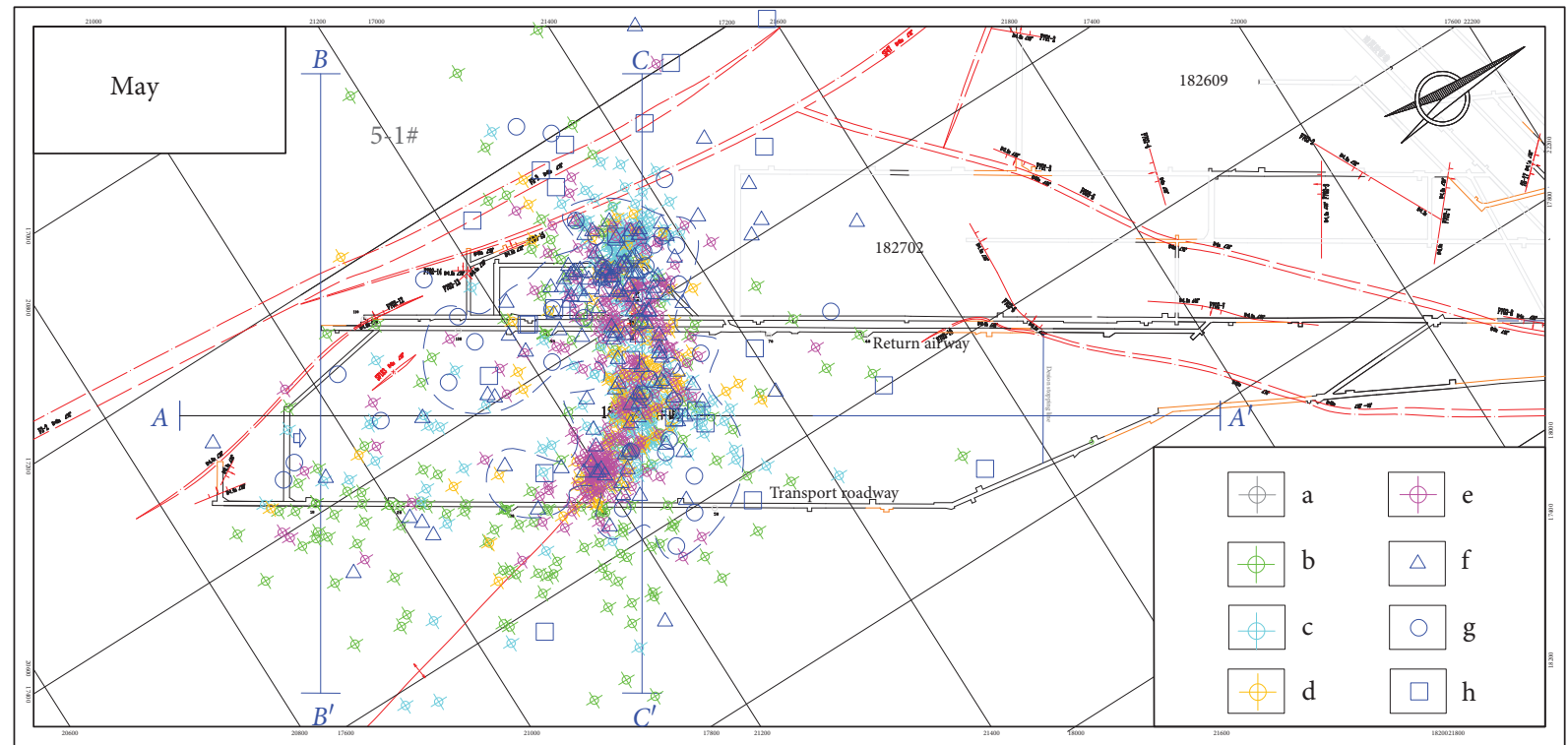

FiguRE 12: Distribution plan of microseismic events in May. a: shallow of 2\# coal; b: floor of 2\# coal--floor of Yeqing limestone; c: floor of Yeqing limestone-floor of Fuqing limestone; d: floor of Fuqing limestone-floor of Daqing limestone; e: floor of Danqing limestone-roof of Ordovician limestone; f: Ordovician limestone (0-50 m); g: Ordovician limestone (51-150 m); h: Ordovician limestone (150 m-deep part).

4.5.2. The Relationship between the Variation of Water Pressure in Different Aquifers and Microearthquakes. The water pressure of aquifers with different depths is different, which leads to different microseismic monitoring data. According to the water pressure data collected by the mine hydrological monitoring unit, there is a clear difference in water pressure between the Yeqing limestone aquifer and the mountain blue limestone aquifer. The water pressure of the Yeqing limestone aquifer ranges from 1.6 to $7.1 \mathrm{MPa}$. The water pressure of the rock aquifer ranges from 1.3 to 8.8 $\mathrm{MPa}$. According to the microseismic profile, it can be seen that the number of microseismic events in the mountain bladder limestone aquifer is more than that of the Yeqing limestone aquifer, which can indicate that there is a certain connection between water pressure and microseismic events, and the increase in water pressure will lead to the increase in the number of microseismic events.

4.6. Microseismic Characteristics When Passing through the Grouting Abnormal Area. There are two abnormal grouting areas on the working face. When the working face passes through the abnormal grouting area, the microseismic monitoring data has changed significantly compared with 


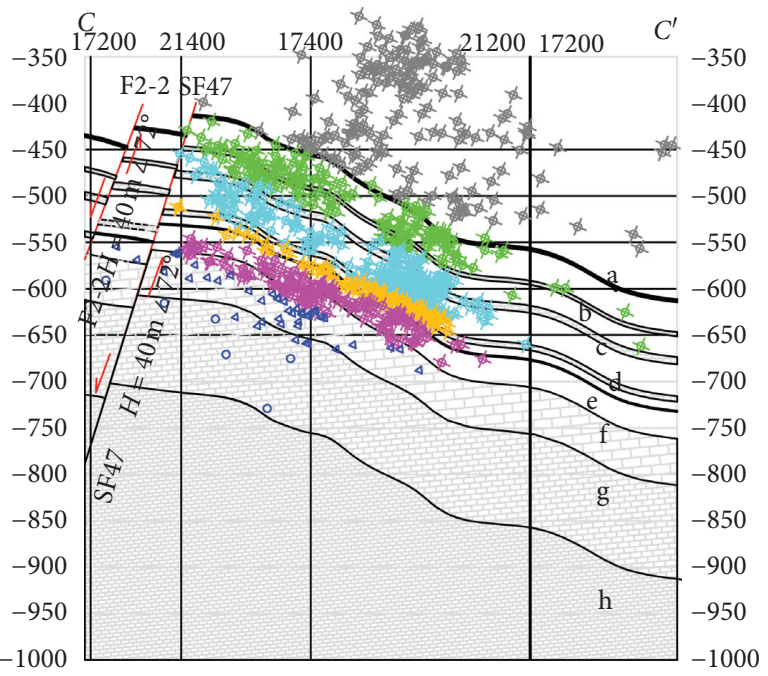

Figure 13: Distribution profile of microseismic events in April. a: 2\# coal seam; b: Yeqing limestone; c: Shanfuqing limestone; d: Daqing limestone; e: 9\# coal seam; f: Ordovician limestone; g: Ordovician limestone $(50 \mathrm{~m})$; h: Ordovician limestone (100 m).

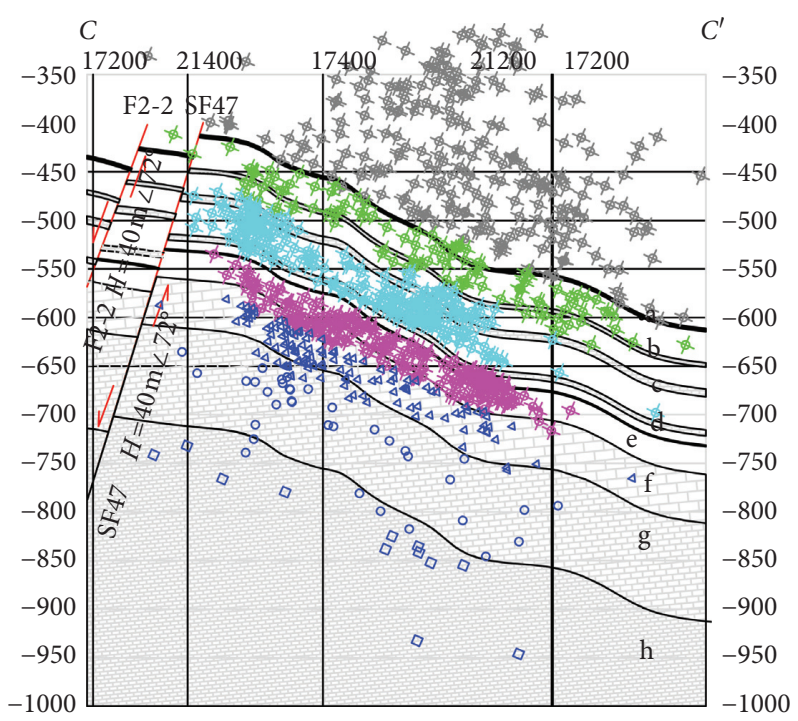

Figure 14: Distribution profile of microseismic events in May. a: 2\# coal seam; b: Yeqing limestone; c: Shanfuqing limestone; d: Daqing limestone; e: 9\# coal seam; f: Ordovician limestone; g: Ordovician limestone ( $50 \mathrm{~m})$; h: Ordovician limestone (100 m).

the normal grouting area. When the working face passes the l\# grouting anomaly zone, the accumulated energy of microseismic events from June 26th to July 10th, 2019, is $16575760 \mathrm{~J}$, of which the minimum energy of the microseismic event on July 9 th is $7322 \mathrm{~J}$ and the maximum energy of July 5 th is $13242289 \mathrm{~J}$. The average is $1105051 \mathrm{~J}$. When the working face passes the 2\# grouting abnormal area, the accumulated energy of microseismic events from September 6th to September 20th, 2019, is 29697036 J, of which the lowest energy on September 6th is 1906 J and the highest energy on September 15th is $7154687 \mathrm{~J}$, with an average of 1979802 J. Therefore, it can be seen that when the working face gradually approaches and passes through the grouting abnormal area, the number of microseismic events will increase significantly. However, from the perspective of the energy of microseismic events, most of the increased microseismic events (when the working face approaches the grouting abnormal area) are mining activities. The roof collapse event caused by the incident is manifested as a large number of small energy events; when passing through the grouting abnormal area, the surrounding rock deep in the floor ruptures, resulting in microseismic events, manifested in the form of large energy and large number of events. 


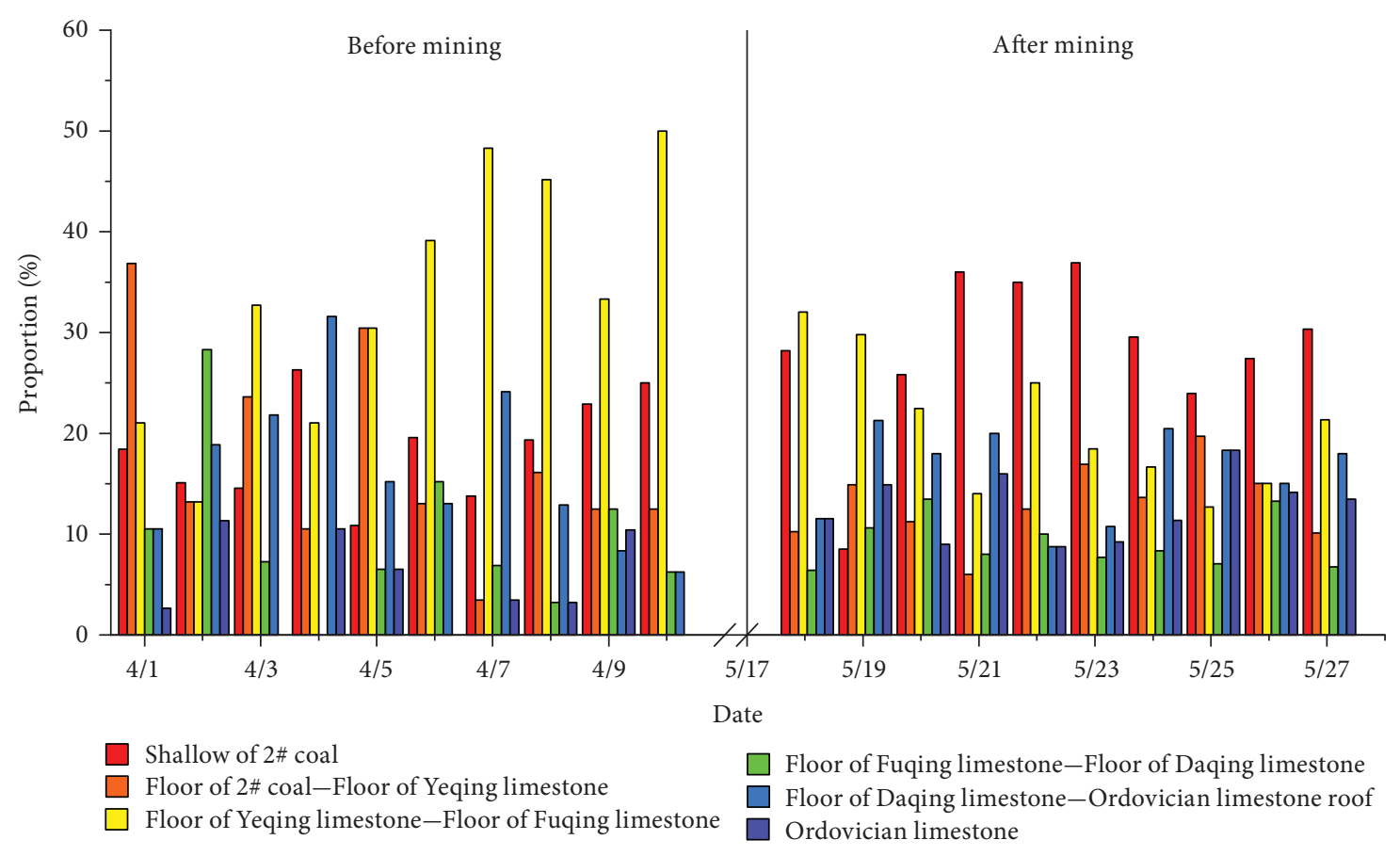

FIGURE 15: The proportion of microseismic events in each aquifer.

\section{Conclusion}

Through the quantitative processing of the data collected by the microseismic monitoring system, a spatial distribution diagram of microseismic events, a comparison diagram of the number of events, and a comparison diagram of amplitudes have been established, combined with the actual measurement before and after mining in the Wutongzhuang Coal Mine. The following can be concluded:

(1) There is a large-scale weak zone in the floor of Yeqing-the floor of Fuqing area in front of the working face, and the cause of its dislocation is geological tectonic movement.

(2) When the large-scale weak zone under the floor of the working face is misaligned, the microseismic feature is that the number of events is small, the event spatial distribution is concentrated, the energy magnitude is high, the amplitude is high, and the proportion of large events in microseismic events is greater than that of small ones. The characteristics of microseismic events caused by working face stopping are the following: the number of events is large, the distribution of events is relatively loose, the roof and floor are more distributed, but the energy level is small, the amplitude is also small, and the proportion of small and medium events in microseismic events is greater than that of large ones.

It can be seen that there is a weak zone dominated by faults under the floor of Wutongzhuang Coal Mine 182703 working face. When it is misaligned by the influence of geological tectonic movement, it will trigger a large microseismic event, which is different from the microseismic event caused by mining activities.
The microseismic event caused by the weak zone dislocation has a large energy level and is more dangerous to the mine. It will aggravate the changes in the stability of the floor aquifer during the mining and increase the possibility of water inrush from the coal floor. Therefore, measures such as floor grouting should be taken in time to enhance coal mine safety.

At the same time, it should also be noted that there is no tectonic activity caused by mining at the current working face excavation. Therefore, this article only compares and analyzes the microseisms caused by tectonic activity and those caused by mining. If there is tectonic activity caused by mining, it is inferred that the slight earthquake may be more severe.

\section{Data Availability}

The data used to support the findings of this study are available from the corresponding author upon request.

\section{Conflicts of Interest}

The authors declare that they have no conflicts of interest.

\section{Acknowledgments}

This work was supported by the National Natural Science Foundation of China (51804309), Yue Qi Young Scholar Project (2019QN02) and Distinguished Scholar Project (2017JCB02) from China University of Mining and Technology (Beijing), and Joint Fund of State Key Laboratory of Coal Resources and Safe Mining and Beijing Outstanding Young Scientist Program (Grants nos. SKLCRSM20LH01 and BJJWZYJH01201911413037). 


\section{References}

[1] M. G. Qian, X. X. Liao, J. L. Xu et al., The Key Layer Theory of Rock Formation Control, China University of Mining and Technology Press, Xuzhou, China, 2003.

[2] H. W. Jin, S. L. Yu, G. Xu et al., "Quantitative evaluation method of water hazard risk in coal mine," Journal of Safety Science and Technology, vol. 16, no. 4, pp. 107-113, 2020.

[3] Q. Wu, "Progress, problems and prospects of prevention and control technology of mine water and reutilization in China," Journal of China Coal Society, vol. 39, no. 5, pp. 795-805, 2014.

[4] Y. D. Jiang, K. K. Lu, Y. X. Zhao et al., "Similar simulation test for breakage law of working face floor in coal mining above aquifer," Chinese Journal of Rock Mechanics and Engineering, vol. 30, no. 8, pp. 1571-1578, 2011.

[5] Q. B. Zhao, "Ordovician limestone karst water disaster regional advanced governance technology study and application," Journal of China Coal Society, vol. 39, no. 6, pp. 1112-1117, 2014.

[6] X. X. Miao and H. B. Bai, "Water-resisting characteristics and distribution rule of carbonate strata in the top of Ordovician in North China," Journal of China Coal Society, vol. 36, no. 2, pp. 185-193, 2011.

[7] Z. L. Zhang, Y. F. Gao, J. Wu, and S.-M. Wei, "Discussion on the technical system of solid prevention and control on mine flooding," Journal of China Coal Society, vol. 38, no. 3, pp. 378-383, 2013.

[8] P. D. Zhang, W. Yan, W. Q. Zhang et al., "Study on factors influencing groundwater inrush inducedby backstopping of a coal seam with a hidden fault," Journal of Mining \& Safety Engineering, vol. 35, no. 4, pp. 765-772, 2018.

[9] X. H. Xie, B. Y. Su, Y. F. Gao et al., "Numerical study on water inrush above a confined aquifer in coal mining using hydrofracturing," Chinese Journal of Rock Mechanics and Engineering, vol. 24, no. 6, pp. 987-993, 2005.

[10] Z. M. Xu, Y. J. Sun, S. Y. Gong et al., "Monitoring and numerical simulation of formation of water inrush pathway caused by coal mining above confined water with high pressure," Chinese Journal of Rock Mechanics and Engineering, vol. 31, no. 8, pp. 1698-1704, 2012.

[11] J. B. Li and Y. C. Xu, "Mechanical model of the collapse column water inrush prevention considering the confined water seepage and its application," Journal of China University of Mining \& Technology, vol. 45, no. 2, pp. 217-224, 2016.

[12] Q. B. Zhao, B. W. Zhao, Y. G. Fu et al., "Research on key technology to control Ordovician limestone water disaster on surface region of deep mining depth mine," Coal Science and Technology, vol. 44, no. 8, pp. 14-20, 2016.

[13] S. N. Dong, H. Wang, and W. Z. Zhang, "Judgement criteria with utilization and grouting reconstruction of top Ordovician limestone and floor damage depth in North China coal field," Journal of China Coal Society, vol. 44, no. 7, pp. 2216-2226, 2019.

[14] H. Wang, A. K. Luo, S. N. Dong et al., "Utilizability research on the top layer of Ordovician limestone as aquiclude of coal seam floor," China Coal, vol. 44, no. 1, pp. 34-38, 2018.

[15] Y. C. Xu, P. F. Li, W. Y. Guo et al., "Study on the damage of floor rock mass before mining in lower coal seam working face above the confined water," Metal Mine, no. 10, pp. 119-125, 2019.

[16] S. J. Ma, "Research on comprehensive geophysical prospecting technology for long coal face with high confined water," Mining Safety \& Environmental Protection, vol. 44, no. 6, pp. 65-68, 2017.
[17] S. Y. Wei, X. M. Chen, and Y. C. Xu, "Research on roadway stabilization passing fault fractured zone above high water pressure of quifer," Coal Science and Technology, vol. 41, no. S2, pp. 8-10, 2013.

[18] J. T. Chen, Q. Wu, L. M. Yin et al., "Law of crack evolution in floor rock mass above high confined water," Coal Science and Technology, vol. 46, no. 7, pp. 54-60, 2018.

[19] Y. C. Xu and Y. B. Gao, "Theoretical analysis on working face cross-fault under high water pressure condition," Safety in Coal Mines, vol. 46, no. 9, pp. 192-195, 2015.

[20] X. Wang, W. Zhu, J. Xu, H. Han, and X. Fu, "Mechanism of overlying strata structure instability during mining below unconsolidated confined aquifer and disaster prevention," Applied Sciences, vol. 11, no. 4, Article ID 1778, 2021.

[21] H. T. Yu, S. Y. Zhu, and Y. Chen, "Comparative analysis of water inrush from the deep coal floor by mining above the confined aquifer," Journal of Mining Science, vol. 55, no. 3, pp. 407-413, 2019.

[22] H. F. Duan and L. J. Zhao, "New evaluation and prediction method to determine the risk of water inrush from mining coal seam floor," Environmental Earth Sciences, vol. 80, no. 1, pp. 1-13, 2021.

[23] Y. B. Li, "The new development of coal mine geophysical prospecting in China," China Mining Magazine, vol. 21, no. S1, pp. 449-451, 2012.

[24] Q. Ge and L. Han, "Direct imaging structure beneath the source using microseismic data," Chinese Journal of Geophysics-Chinese Edition, vol. 62, no. 10, pp. 3988-3999, 2019.

[25] J. F. Lou, F. Q. Gao, J. H. Yang et al., "Characteristics of evolution of mining-induced stress field in the longwall panel: insights from physical modeling," International Journal of Coal Science and Technology, 2021.

[26] H. Wang, Q. Guo, T. Alkhalifah et al., "Regularized elastic passive equivalent source inversion with full-waveform inversion: application to a field monitoring microseismic data set," Geophysics, vol. 85, no. 6, pp. KS207-KS219, 2020.

[27] X. J. Hao, W. S. Du, and Y. X. Zhao, "Dynamic tensile behaviour and crack propagation of coal under coupled staticdynamic loading," International Journal of Mining Science and Technology, vol. 30, no. 5, pp. 659-668, 2020.

[28] X. J. Hao, Y. N. Wei, and K. Yang, "Anisotropy of crack initiation strength and damage strength of coal reservoirs," Petroleum Exploration and Development, vol. 48, no. 1, pp. 243-255, 2021.

[29] X. J. Hao, Q. Zhang, and Z. W. Sun, "Effects of the major principal stress direction respect to the long axis of a tunnel on the tunnel stability: physical model tests and numerical simulation," Tunnelling and Underground Space Technology, vol. 114, no. 7, Article ID 103993, 2021.

[30] Y. Zheng, C. Chen, T. Liu et al., "A new method of assessing the stability of anti-dip bedding rock slopes subjected to earthquake," Bulletin of Engineering Geology and the Environment, vol. 80, no. 4, pp. 1-18, 2021.

[31] X. L. Zhang, R. S. Jia, X. M. Lu et al., "Identification of blasting vibration and coal-rock fracturing microseismic signals," Applied Geophysics, vol. 15, no. 2, pp. 280-289, 2018.

[32] D. Chen, N. Li, and E. Y. Wang, "Reliability assessment of the hydraulic fracturing process in coal mine based on the analysis of micro-seismic source parameters," Natural Resources Research, vol. 16, 2021.

[33] A. A. S. Amad, A. A. Novotny, and B. B. Guzina, "On the fullwaveform inversion of seismic moment tensors," International Journal of Solids and Structures, vol. 202, pp. 717-728, 2020. 
[34] R. Estay, J. Vallejos, C. Pavez, and M. Brönner, “A comparison of characteristic parameters of mining related and tectonic seismic aftershock sequences," International Journal of Rock Mechanics and Mining Sciences, vol. 128, p. 11, 2020.

[35] G. F. Liu, Q. Jiang, G. L. Feng, D. F. Chen, B. R. Chen, and Z. N. Zhao, "Microseismicity-based method for the dynamic estimation of the potential rockburst scale during tunnel excavation," Bulletin of Engineering Geology and the Environment, vol. 80, no. 5, pp. 3605-3628, 2021.

[36] Y. Q. Guan, "Preliminary research on genesis of geothermal abnormalism in Wutongzhuang mine," Coal Geology of China, vol. 14, no. 3, pp. 37-39, 2002.

[37] J. J. Zhao and Q. L. Liu, "Analysis on the geothermal origin in Wu Tong-ZhuangMine," Hebei Coal, no. 3, pp. 14-15, 2010. 